J. Dairy Sci. 96:4751-4758

http://dx.doi.org/10.3168/jds.2012-6538

(C) American Dairy Science Association ${ }^{\circledR}, 2013$.

\title{
Characterization of Kentucky dairy producer decision-making behavior
}

\author{
R. A. Russell and J. M. Bewley ${ }^{1}$ \\ Department of Animal and Food Sciences, University of Kentucky, Lexington 40546
}

\begin{abstract}
To address dairy clientele needs, industry professionals need to understand how dairy producers make decisions. A survey was distributed to all licensed Kentucky milk producers $(\mathrm{n}=1,074)$ to better understand factors that influence dairy producer decisions. A total of 236 surveys were returned; 7 were omitted because they were incomplete, leaving 229 for subsequent analyses (21\% response rate). The survey consisted of questions about dairy operational success criteria, decision evaluation criteria, information sources, and technology adoption. The mean response to each survey question was calculated after assigning the following numeric values to producer response categories: $1=$ not important, $3=$ important, $5=$ very important. The most important source of influence or information in decision making was advice from consultants, nutritionists, and veterinarians $(3.70 \pm 1.23)$, followed by consultation with business partners and family members $(3.68 \pm 1.29)$, and intuition and gut feeling $(3.10 \pm 1.45)$. Producers with large herds ( $\geq 200$ cows) relied more heavily on information from consultants, nutritionists, and veterinarians and on employee input than did producers with small herds (1 to 49 cows). Producers with small herds did not use effect on employee morale as a criterion to evaluate decisions as much as those with larger herds did. In regard to adoption of automated monitoring technologies, producers indicated that modest adoption rates were a result of (1) not being familiar with technologies that are available (55\%), (2) undesirable cost to benefit ratios (42\%), and (3) too much information provided without knowing what to do with it (36\%). As herd size increased, the percentage of producers selecting poor technical support and training and compatibility issues as reasons for slow adoption of automated technologies increased. This insight into dairy producer decision making should help industry professionals address dairy producer issues and concerns.
\end{abstract}

Key words: dairy extension, survey, decision making

Received December 30, 2012.

Accepted March 6, 2013.

${ }^{1}$ Corresponding author: jbewley@uky.edu

\section{INTRODUCTION}

Dairy farm sustainability is a direct result of dairy producer decision-making processes. Understanding how dairy producers make decisions is important to extension and industry professionals as they strive to increase adoption of best management practices. Performance of the dairy herd is directly related to management practices employed (Carley and Fletcher, 1986). To increase productivity, producers have adopted new management technologies and techniques (King and Rollins, 1999). Some of these changes include an increased adoption of computer monitoring technologies and an increase in using Internet resources. Although technology use has increased, adoption rates in the dairy industry have been slow compared with other industries. Dairy producers may not use the Internet as extensively as other business managers. Maurer and Fast (2007) determined that only $56 \%$ of surveyed Kentucky dairy producers had Internet access in their homes, and $62 \%$ of producers indicated that the Internet was not an effective information delivery method. Slow adoption of new technologies is not limited to computers and the Internet; automated monitoring systems have been adopted slowly in the dairy industry despite widespread availability (Huirne et al., 1997; Gelb et al., 2001). Using computerized record systems and automated monitoring systems improve on-farm management and decision making (Spahr, 1993). Despite widespread availability, adoption of these technologies in the dairy industry has been relatively sparse to date (Huirne et al., 1997; Gelb et al., 2001).

Extension professionals dedicate considerable time toward development of targeted local, regional, and state meetings to address dairy producer educational needs (Chase et al., 2006). Dairy extension programming efforts must continually evolve to meet the needs of a changing clientele base (Hutjens et al., 2004). Knowing dairy producers' management practices and decisionmaking behavior is important for extension educators who develop educational programs (Zimmerman et al., 2006). Understanding dairy producers' management practices helps extension professionals understand how producers make decisions. This, in turn, helps extension professionals design producer-oriented programs. 
To evaluate decision-making processes, a survey was designed to ask Kentucky dairy producers directly about how they make decisions. The objectives of this survey were to (1) evaluate decision-making processes, (2) determine the cause of slow technology adoption, (3) determine sources of information for making decisions, (4) assess how producers measure success, and (5) determine criteria used for evaluating decisions.

\section{MATERIALS AND METHODS}

A 5-page survey was distributed to all licensed milk producers in Kentucky $(\mathrm{n}=1,074)$. Surveys were mailed on July 1, 2008. To maintain producer anonymity, each survey was labeled with a number that corresponded to a name and address. The list of producers' names and addresses was only used to determine who to send follow-up surveys to and was not referred to after final survey distribution. Two weeks after the first mailing, a follow-up postcard was mailed to remind producers to return the survey. On August 1, 2008, the survey was resent to producers who had not returned the initial survey. A total of 236 surveys were returned; 7 were omitted because they were incomplete, leaving 229 for subsequent analyses (21\% response rate). The survey consisted of questions about dairy operational success criteria, decision evaluation criteria, information sources, and technology adoption. For some questions, producers were asked to select a number on a 1 to 5 Likert (1932) scale, with 1 indicating "not important" and 5 indicating "very important."

Data were entered into an online survey tool (KeySurvey, Braintree, MA). Statistical analyses were conducted using SAS software (SAS Institute Inc., Cary, NC). Surveys were categorized by herd size, production system, region within the state, operator age, and production level. Herds were categorized by herd size to reflect management similarities as follows: 1 to 49,50 to 99,100 to 149,150 to 199 , and 200 to 1,200 cows. Producers were asked to categorize their dairy production system by selecting the option that best described their situation: pasture grazing, partial confinement, or total confinement. Regions within the state were categorized as East, South Central, North Central, West, and Far West. Operator age categories were defined as follows: $<35,35$ to 44,45 to 54,55 to 64 , and $\geq 65$ yr of age. Herds were categorized into terciles based on reported milk production levels as follows: low $(<22.7 \mathrm{~kg} /$ cow per day), mid (22.7 to $26.4 \mathrm{~kg}$ ), and high ( $\geq 26.4 \mathrm{~kg}$ ). Least squares means among categories were calculated for quantitative variables using the GLM procedure of SAS. Tukey's test for multiple comparisons was used and statistical differences were considered significant using a 0.05 significance level. For qualitative variables, $\chi^{2}$ analyses were conducted using the FREQ procedure of SAS. Statistical differences were considered significant at a 0.05 significance level.

\section{RESULTS AND DISCUSSION}

\section{Operational Success Criteria}

Descriptive statistics of surveyed herds and extension programming assessment were presented in Russell and Bewley (2011). When producers were asked to determine how they measured their operation's success, the most frequent response was ability to pay operating expenses without incurring unnecessary debt $(92 \%)$, followed by well-being of animals in the herd (83\%), producing superior quality milk (76\%), keeping a balance in the checking account (73\%), quality of life $(67 \%)$, production per cow $(58 \%)$, return on assets or return on equity $(52 \%)$, net farm income per cow (50\%), time off and time with family (44\%), minimizing tax obligations (40\%), reputation among other dairy producers (18\%), and performance compared with other dairy producers (16\%). Many of the criteria used by producers to evaluate their success were financial measures, including ability to pay expenses, keeping a balance in the checkbook, return on assets, net farm income, and minimizing tax obligations. However, from these results, it is clear that human factors are also quite important. Many producers indicated that quality of life, time off, time with family, and reputation among other dairy producers were criteria they used to evaluate their success. In an era where dairy producers are under increased scrutiny for how they care for their animals, perhaps the most interesting result from this question was that $83 \%$ of producers indicated that well-being of the animals in the herd was one of the ways they measure their success. Milk quality and production per cow were also listed as criteria for success evaluation.

When categorized by herd size (Table 1 ), producers with $\geq 200$ cows were more likely $(P<0.05)$ to choose minimizing tax obligations as a form of dairy operational success criteria than producers with $<200$ cows. As herd size increased, the number of managers choosing production per cow as a way to evaluate dairy operational success increased. These results may demonstrate an increased focus on business and production among larger herds. No differences among herd size categories were observed for the following success criteria: ability to pay operating expenses without incurring unnecessary debt, keeping a balance in the checkbook, net farm income per cow, performance compared with other dairy producers, producing superior quality milk, quality of life, reputation among other dairy producers, 
Table 1. Criteria used to measure dairy operational success among herd size categories as indicated by dairy operations responding to the Kentucky dairy extension survey ${ }^{1}$

\begin{tabular}{|c|c|c|c|c|c|c|}
\hline \multirow[b]{2}{*}{ Criterion } & \multicolumn{5}{|c|}{ Herd size } & \multirow[b]{2}{*}{$\chi^{2}$} \\
\hline & $\begin{array}{c}1 \text { to } 49 \\
(\mathrm{n}=80)\end{array}$ & $\begin{array}{l}50 \text { to } 99 \\
(\mathrm{n}=84)\end{array}$ & $\begin{array}{c}100 \text { to } 149 \\
(\mathrm{n}=25)\end{array}$ & $\begin{array}{c}150 \text { to } 199 \\
(\mathrm{n}=12)\end{array}$ & $\begin{array}{c}\geq 200 \\
(\mathrm{n}=12)\end{array}$ & \\
\hline Keeping a balance in the checking account & 76 & 77 & 67 & 58 & 64 & 0.48 \\
\hline Minimizing tax obligations & 30 & 46 & 42 & 33 & 73 & 0.04 \\
\hline Net farm income per cow & 48 & 48 & 58 & 33 & 82 & 0.14 \\
\hline Production per cow & 53 & 55 & 63 & 67 & 82 & 0.36 \\
\hline Quality of life & 65 & 68 & 75 & 42 & 73 & 0.35 \\
\hline Reputation among other dairy producers & 16 & 15 & 17 & 0 & 36 & 0.22 \\
\hline Return on assets or return on equity & 44 & 57 & 50 & 33 & 73 & 0.16 \\
\hline Time off and time with family & 36 & 50 & 46 & 25 & 45 & 0.30 \\
\hline Well-being of animals in the herd & 88 & 76 & 79 & 75 & 91 & 0.34 \\
\hline
\end{tabular}

${ }^{1}$ Percentage of producers indicating that a criterion is used.

return on assets and return on equity, time off or time with family, or well-being of animals in the herd.

\section{Decision-Making Criteria}

Criteria most chosen by producers to evaluate decisions were ability to generate cash flow (95\%), followed by availability of funds to pay for investments $(81 \%)$ and effect on the business's long-term financial performance $(71 \%)$, effect on the business's short-term financial performance $(55 \%)$, government regulations (43\%), time needed to implement decision (42\%), prestige, pride, or reputation associated with the outcome $(27 \%)$, effect on employee morale $(22 \%)$, anticipated reaction from consumers $(16 \%)$, what your neighbor is doing (7\%), and desire to be the first to use a new practice $(3 \%)$. In contrast to overall operational success, producers placed less emphasis on noneconomic factors for making individual decisions. Prestige, pride, or reputation $(27 \%)$, effect on employee morale $(22 \%)$, anticipated reaction from consumers $(16 \%)$, what the neighbor is doing (7\%), and desire to be the first to use a new practices were listed less frequently than economic criteria. This difference likely reflects that, although dairy producers evaluate their whole operation success on both business and human factors, individual decisions are influenced more by economic factors. This difference in philosophies could explain the struggles that many producers have in attaining financial and personal success.

As herd size increased, the percentage of producers considering the effect of a decision on the business's short-term financial performance increased $(P=0.01$; Table 2). Producers with 150 to 199 cows were more likely $(P<0.05)$ to use time needed to implement a decision as a criterion compared with producers with
200 to 1,200 cows. As herd size increased, the percentage of producers who considered the effect of a decision on employee morale increased $(P<0.01)$. This is a logical result because larger herds generally have more employees. No differences among herd size categories were observed for the following decision criteria: ability to generate cash flow, anticipated reaction from consumers, availability of funds to pay for investments, desire to be the first to use a new practice, government regulations, prestige associated with decision outcome, or neighbor activities. When categorized by age (Table 3 ), producers $\geq 65$ yr were more likely $(P<0.05)$ to use government regulations as a criterion than producers $<35$ yr. Producers $<35$ yr were less likely $(P<0.05)$ to use prestige, pride, or reputation associated with the outcome as a criterion compared with producers $\geq 65$ yr.

\section{Information Sources}

Having reliable sources of information is important for producers when making decisions. Producers were asked about the importance of sources of information. Producers indicated advice from consultants, nutritionists, and veterinarians was the most important source of information, with a mean response of $3.70 \pm 1.23$, followed by consultation with business partners and family members $(3.68 \pm 1.29)$, intuition and gut feeling $(3.10 \pm 1.45)$, advice from cooperative extension $(3.05$ $\pm 1.25)$, and printed magazines and publications (3.05 \pm 1.21) (Table 4). Maurer and Fast (2007) indicated that producers relied heavily upon dairy magazines and newspapers, other dairy producers, and cooperative extension services, whereas Wilson et al. (1988) indicated that producers ranked communication with hired labor above the use of consultants. King and Rollins (1999) 
Table 2. Criteria used to evaluate decisions among herd size categories as indicated by dairy operations responding to the Kentucky dairy extension survey ${ }^{1}$

\begin{tabular}{|c|c|c|c|c|c|c|}
\hline Criterion & \multicolumn{5}{|c|}{ Herd size } & $\chi^{2}$ \\
\hline Anticipated reaction from consumers & 18 & 12 & 16 & 8 & 9 & 0.78 \\
\hline Availability of funds to pay for investments & 78 & 80 & 80 & 92 & 91 & 0.74 \\
\hline Desire to be the first to use a new practice & 3 & 0 & 8 & 0 & 0 & 0.13 \\
\hline Effect on the business's short-term financial performance & 42 & 55 & 60 & 83 & 82 & 0.01 \\
\hline Effect on employee morale & 6 & 19 & 36 & 42 & 64 & $<0.01$ \\
\hline Prestige, pride, or reputation associated with the outcome & 23 & 30 & 36 & 33 & 27 & 0.70 \\
\hline Time needed to implement decision & 30 & 51 & 44 & 58 & 27 & 0.06 \\
\hline What your neighbor is doing & 10 & 5 & 0 & 8 & 0 & 0.30 \\
\hline
\end{tabular}

${ }^{1}$ Percentage of producers indicating influence of each criterion.

indicated that producers chose university specialists as the most trustworthy sources of information. When categorized by herd size (Table 5), producers with 1 to 49 cows were significantly less likely $(P<0.05)$ to use advice from consultants, nutritionists, and veterinarians as a source of information for decision making than producers with 200 to 1,200 cows. Producers with 200 to 1,200 cows were significantly more likely $(P<0.05)$ to use employee input as an information source than producers with 1 to 49 cows. This is rational, because larger farms tend to have more employees. Sources of information were also categorized by production system (Table 6). Producers with a total confinement system were significantly more likely $(P<0.05)$ to use advice from consultants, nutritionists, and veterinarians as a source of information than producers with pasture-grazing or partial confinement systems. Total confinement systems tend to be larger farms, which also indicated a greater importance of information from consultants, nutritionists, and veterinarians. Producers with partial confinement systems were significantly more likely $(P$ $<0.05)$ to use consultation with neighboring farmers as an information source than producers with a total confinement system. Producers with a pasture-grazing system were significantly less likely $(P<0.05)$ to use informal calculations to examine financial impact (e.g., paper, spreadsheets) than producers with a total confinement system.

\section{Technology Adoption}

Adoption of new technologies among dairy producers has been slow to date (Huirne et al., 1997; Gelb et al., 2001). Farm profitability can be increased through farm modernization that focuses on increased milk production and employee efficiency (Bewley et al., 2001). Improving efficiency of production has provided an important opportunity for dairy farmers in the United

Table 3. Criteria used to evaluate decisions among age (of primary operator) categories as indicated by dairy operations responding to the Kentucky dairy extension survey ${ }^{1}$

\begin{tabular}{|c|c|c|c|c|c|c|}
\hline \multirow[b]{2}{*}{ Criterion } & \multicolumn{5}{|c|}{ Age of primary operator $(\mathrm{yr})$} & \multirow[b]{2}{*}{$\chi^{2}$} \\
\hline & $\begin{array}{c}<35 \\
(\mathrm{n}=28)\end{array}$ & $\begin{array}{l}35 \text { to } 44 \\
(\mathrm{n}=32)\end{array}$ & $\begin{array}{l}45 \text { to } 54 \\
(\mathrm{n}=58)\end{array}$ & $\begin{array}{l}55 \text { to } 64 \\
(\mathrm{n}=64)\end{array}$ & $\begin{array}{c}\geq 65 \\
(\mathrm{n}=26)\end{array}$ & \\
\hline Anticipated reaction from consumers & 19 & 16 & 18 & 11 & 8 & 0.67 \\
\hline Availability of funds to pay for investments & 81 & 75 & 82 & 86 & 72 & 0.53 \\
\hline Desire to be the first to use a new practice & 4 & 0 & 4 & 2 & 0 & 0.67 \\
\hline Effect on the business's short-term financial performance & 44 & 53 & 63 & 53 & 56 & 0.58 \\
\hline Effect on employee morale & 11 & 25 & 23 & 19 & 24 & 0.67 \\
\hline Prestige, pride, or reputation associated with the outcome & 22 & 25 & 32 & 20 & 52 & 0.04 \\
\hline Time needed to implement decision & 33 & 25 & 51 & 47 & 32 & 0.09 \\
\hline What your neighbor is doing & 4 & 16 & 4 & 3 & 12 & 0.08 \\
\hline
\end{tabular}

${ }^{1}$ Percentage of producers indicating influence of each criterion. 


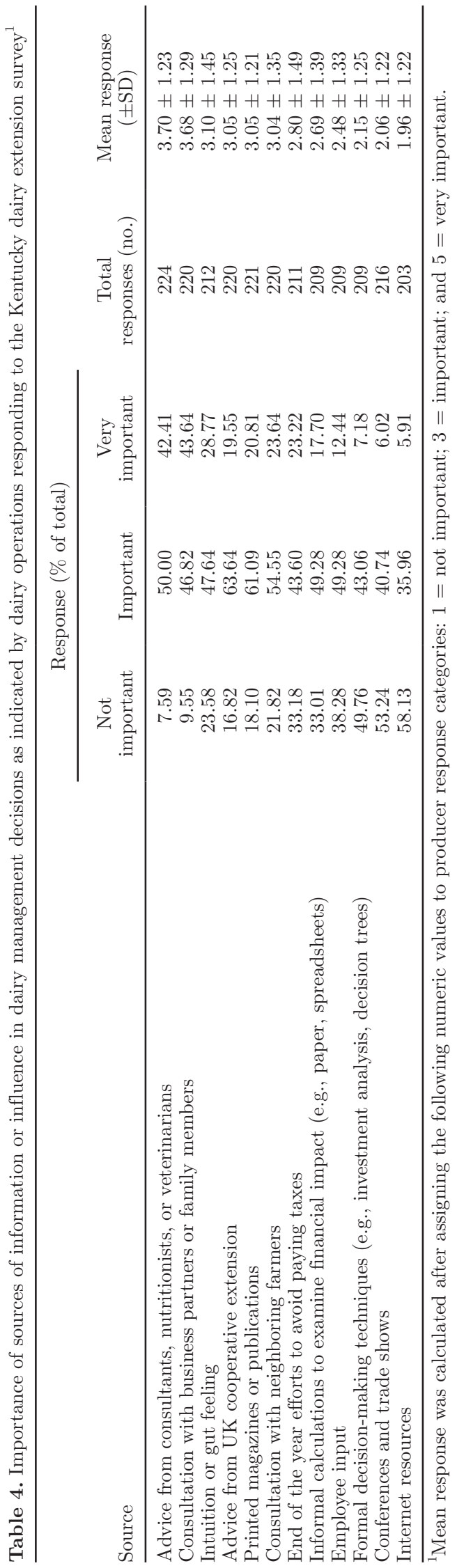

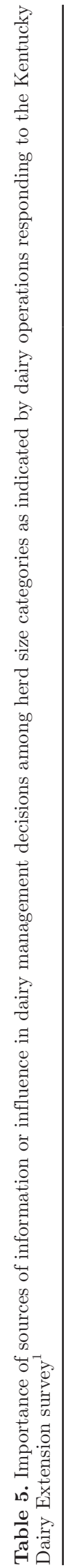

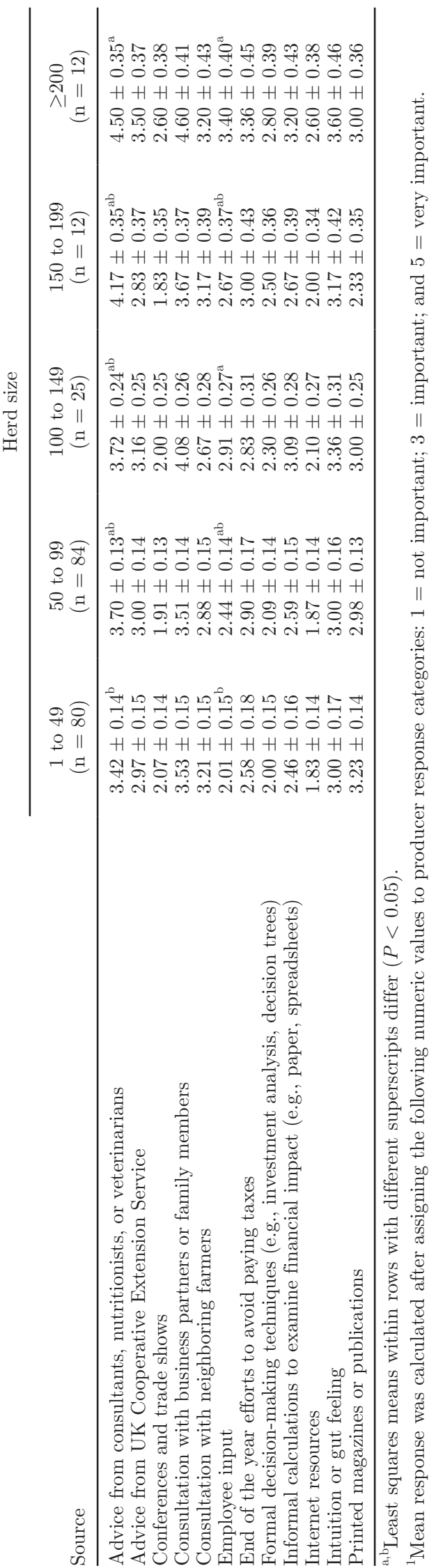


Table 6. Importance of sources of information or influence in dairy management decisions among production systems as indicated by dairy operations responding to the Kentucky Dairy Extension survey ${ }^{1}$

\begin{tabular}{|c|c|c|c|}
\hline Source & $\begin{array}{l}\text { Pasture-grazing } \\
\quad(\mathrm{n}=98)\end{array}$ & $\begin{array}{c}\text { Partial } \\
\text { confinement } \\
(\mathrm{n}=77)\end{array}$ & $\begin{array}{l}\text { Total confinement } \\
\qquad(\mathrm{n}=29)\end{array}$ \\
\hline Advice from consultants, nutritionists, or veterinarians & $3.40 \pm 0.12^{\mathrm{b}}$ & $3.75 \pm 0.14^{\mathrm{b}}$ & $4.38 \pm 0.22^{\mathrm{a}}$ \\
\hline Conferences and trade shows & $2.08 \pm 0.12$ & $1.88 \pm 0.14$ & $2.14 \pm 0.23$ \\
\hline Consultation with business partners/family members & $3.51 \pm 0.14$ & $3.69 \pm 0.15$ & $3.97 \pm 0.24$ \\
\hline Consultation with neighboring farmers & $2.92 \pm 0.14^{\mathrm{ab}}$ & $3.24 \pm 0.15^{\mathrm{a}}$ & $2.41 \pm 0.26^{\mathrm{b}}$ \\
\hline Formal decision-making techniques (e.g., investment analysis, decision trees) & $2.10 \pm 0.13$ & $2.04 \pm 0.15$ & $2.43 \pm 0.23$ \\
\hline Informal calculations to examine financial impact (e.g., paper, spreadsheets) & $2.40 \pm 0.14^{\mathrm{b}}$ & $2.71 \pm 0.16^{\mathrm{ab}}$ & $3.14 \pm 0.26^{\mathrm{a}}$ \\
\hline Internet resources & $2.04 \pm 0.12$ & $1.63 \pm 0.15$ & $2.19 \pm 0.23$ \\
\hline Intuition or gut feeling & $3.22 \pm 0.15$ & $2.94 \pm 0.17$ & $3.07 \pm 0.27$ \\
\hline Printed magazines or publications & $3.17 \pm 0.12$ & $3.08 \pm 0.14$ & $2.64 \pm 0.22$ \\
\hline
\end{tabular}

${ }^{\mathrm{a}, \mathrm{b}}$ Least squares means within rows with different superscripts differ $(P<0.05)$.

${ }^{1}$ Mean response was calculated after assigning the following numeric values to producer response categories: $1=$ not important; $3=i m p o r t a n t ;$ and $5=$ very important.

States to achieve an economic advantage (Kellogg et al., 2001). Often, producers may underestimate the value of these technologies because the costs of disease and reduced reproductive performance are not as easy to understand as simply looking at increases in milk production. New technologies give dairy producers the chance to measure physiological, behavioral, and production indicators on individual animals to help improve management strategies. These new technology systems could be critical in helping dairy producers achieve maximum efficiency of production if they were utilized. Knowing the reasons behind slow adoption rates could help extension professionals provide knowledge that is more accurate to dairy producers.

Producers with large dairies (200 to 1,200 cows) are more likely to adopt new technologies than producers with small dairies ( $<200$ cows; Jackson-Smith and Barham, 2000). In our study, producers were asked about potential causes for slow adoption in a "check all that apply" question. Not familiar with new technologies was chosen by the most producers $(55 \%, \mathrm{n}=101)$, followed by undesirable cost to benefit ratio $(42 \%, \mathrm{n}=77)$, and too much information provided without knowing what to do with it $(36 \%, \mathrm{n}=66$; Table 7$)$. When categorized by herd size (Table 8), producers with 200 to 1,200 cows were more likely $(P<0.05)$ to choose not enough time to spend on technology, poor technical support and training, and compatibility issues as concerns for adopting new technology than producers with 1 to 49 cows. No differences among herd size were observed for the following adoption concerns: too much information provided without knowing what to do with it, not reliable or flexible enough, poor integration with other farm systems and software, undesirable cost to benefit ratio, not familiar with technologies that are available, better alternatives or easier to accomplish manually, too difficult or complex to use, not useful or does not address a real need, fear of technology or computer illiteracy, failure in fitting with farmer patterns of work, immature technology or waiting for improvements, lack of standardization, or lack of perceived economic value. Perceived economic returns from investing in a new technology are always a factor influencing technology adoption.

Additional factors affecting technology adoption include degree of impact on resources used in the production process, level of management needed to implement the technology, risk associated with the technology, institutional constraints, producer goals and motivations, and having an interest in a specific technology (Dijkhuizen et al., 1997; van Asseldonk, 1999). Characteristics of the primary decision maker that influence technology adoption include age, level of formal education, learning style, goals, farm size, business complexity, increased tenancy, perceptions of risk, type of production, ownership of a nonfarm business, innovativeness in production, average expenditure on information, and use of the technology by peers and other family members. Producers will only adopt these new technologies if the benefits are clear and the technology is user-friendly (Spahr, 1993). How technologies fit within farmer patterns of work is an important consideration for technology adoption and implementation. Technology manufacturers may focus on the technical aspects of technologies while overlooking important sociological considerations. Simply purchasing a technology does not provide the dairy producer with a return on investment. Rather, successful implementation of the technology involves good technical support and continuous training. The producer concerns listed here 
Table 7. Factors influencing slow adoption rates of automated monitoring technologies as indicated by dairy operations responding to the Kentucky dairy extension survey

\begin{tabular}{lcc}
\hline & \multicolumn{2}{c}{$\begin{array}{c}\text { Producers indicating } \\
\text { influence }\end{array}$} \\
\cline { 2 - 3 } Factor & No. & $(\%)$ \\
\hline Not familiar with technologies that are available & 101 & 55 \\
Undesirable cost to benefit ratio & 77 & 42 \\
Too much information provided without knowing what to do with it & 66 & 36 \\
Not enough time to spend on technology & 56 & 31 \\
Lack of perceived economic value & 55 & 30 \\
Too difficult or complex to use & 53 & 29 \\
Poor technical support or training & 52 & 28 \\
Better alternatives or easier to accomplish manually & 43 & 23 \\
Failure in fitting with farmer patterns of work & 40 & 22 \\
Fear of technology and computer illiteracy & 39 & 21 \\
Not reliable or flexible enough & 33 & 18 \\
Not useful or does not address a real need & 27 & 15 \\
Immature technology or waiting for improvements & 18 & 10 \\
Lack of standardization & 17 & 9 \\
Poor integration with other farm systems and software & 12 & 7 \\
Compatibility issues & 12 & 7 \\
\hline
\end{tabular}

should serve as valuable information for dairy advisors and technology manufacturers in assisting with technology implementation. Clearly, dairy producers consider economic returns as important selection criteria. The reasons listed here also demonstrate the importance of technologies filling real management voids. Technologies should be provided with adequate technical support together with information in a user-friendly format.

\section{CONCLUSIONS}

This study provides dairy industry professionals information about the decision-making processes of dairy producers. Professionals can use this information to guide dairy producers to incorporate best management practices. Understanding how dairy producers make decisions helps us understand the difference between what is technically achievable versus what is actually achieved. Most dairy producers understand how to implement best management practices. However, people factors often impede progress. The results of this survey demonstrate that many noneconomic factors influence dairy producer decisions. At times, dairy producers may make decisions that are less than ideal from an economic perspective. However, they may be the best decision for the operation, as every operation

Table 8. Factors influencing slow adoption rates of automated monitoring technologies by herd size ${ }^{1}$

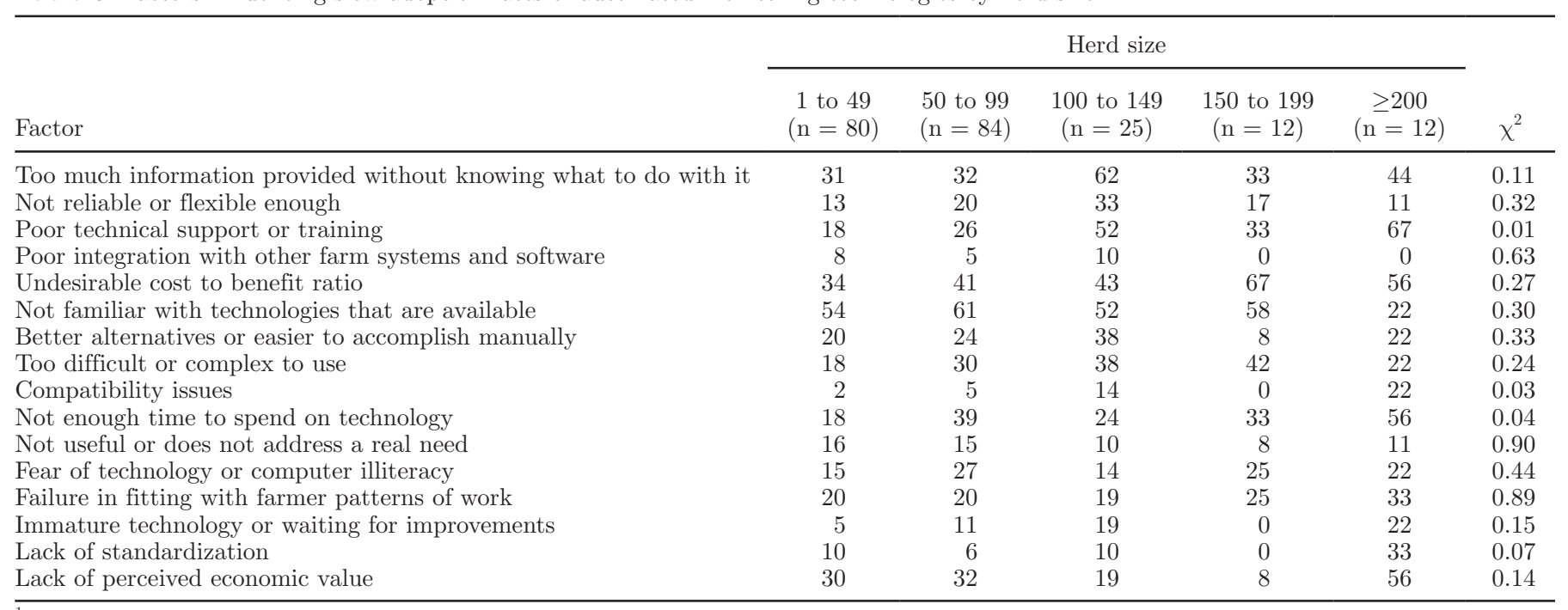

${ }^{1}$ Percentage of producers indicating influence of each factor. 
makes decisions with multiple attributes. Much of this may be reflective of a "way of life" approach to dairy farming. Professionals should focus on the slow adoption of technology by providing dairy producers with accurate information about the technologies. Extension educators can use this information to help guide dairy producers' decisions. Our results suggest that dairy producers may not be as ready for the transition to electronic education as university administrators would like. Traditional programs and printed materials are still effective methods for reaching clientele.

\section{REFERENCES}

Bewley, J., R. Palmer, and D. Jackson-Smith. 2001. Modeling milk production and labor efficiency in modernized Wisconsin dairy herds. J. Dairy Sci. 84:705-716.

Carley, D. H., and S. M. Fletcher. 1986. An evaluation of management practices used by Southern dairy farmers. J. Dairy Sci. 69:2458-2464.

Chase, L. E., L. O. Ely, and M. F. Hutjens. 2006. Major advances in extension education programs in dairy production. J. Dairy Sci. 89:1147-1154.

Dijkhuizen, A. A., R. B. M. Huirne, S. B. Harsh, and R. W. Gardner. 1997. Economics of robot application. Comput. Electron. Agric. 17:111-121.

Gelb, E., C. Parker, P. Wagner, and K. Rosskopf. 2001. Why is the ICT adoption rate by farmers still so slow? Pages 40-48 in Proc. ICAST, Vol. VI. International Conference on Agricultural Science and Technology (ICAST), Beijing, China.

Huirne, R. B. M., S. B. Harsh, and A. A. Dijkhuizen. 1997. Critical success factors and information needs on dairy farms: The farmer's opinion. Livest. Prod. Sci. 48:229-238.
Hutjens, M. F., T. P. Lyons, and K. A. Jacques. 2004. Meeting the educational needs of dairy clientele in 2020. Pages 205-210 in Proc. Nutritional Biotechnology in the Feed and Food Industries; Proc. 20th Alltech Symp. Nottingham University Press, Nottingham, UK.

Jackson-Smith, D. B., and B. Barham. 2000. The changing face of Wisconsin dairy farms: A summary of PATS' research on structural change in the 1990s. Vol. 7. Program on Agricultural Technology Studies, College of Agricultural and Life Sciences, University of Wisconsin-Madison.

Kellogg, D. W., J. A. Pennington, Z. B. Johnson, and R. Panivivat. 2001. Survey of management practices used for the highest producing DHI herds in the United States. J. Dairy Sci. 84(E. Suppl.):E120-E127.

King, R. N., and T. J. Rollins. 1999. An evaluation of an agricultural innovation: Justification of participatory assistance. J. Extension 37:4RIB2. Accessed Dec. 30, 2012. http://www.joe.org/ joe/1999august/rb2.php.

Likert, R. 1932. A technique for the measurement of attitudes. Arch. Psychol. 140:1-55.

Maurer, R. C., and J. A. Fast. 2007. Kentucky dairy producers survey results. Accessed Dec. 30, 2012. http://www.rs.uky.edu/regulatory/milk/survey/E_Dairy_Producer_Comprehensive_Final_Report.pdf.

Russell, R. A., and J. M. Bewley. 2011. Producer assessment of dairy extension programming in Kentucky. J. Dairy Sci. 94:2637-2647.

Spahr, S. L. 1993. New technologies and decision making in high producing herds. J. Dairy Sci. 76:3269-3277.

van Asseldonk, M. A. P. M. 1999. Economic evaluation of information technology applications on dairy farms. PhD Thesis. Wageningen Agricultural University, Wageningen, the Netherlands.

Wilson, P. N., T. R. Luginsland, and D. V. Armstrong. 1988. Risk perceptions and management responses of Arizona dairy producers. J. Dairy Sci. 71:545-551.

Zimmerman, E. K., L. A. Holden, J. E. Park, and J. Hyde. (2006). Relationship of dairy producer management styles to overall return on assets. J. Extension 44:6RIB6. Accessed Dec. 30, 2012. http:// www.joe.org/joe/2006december/rb6p.shtml. 